\title{
TOPÓNIMOS MENORES ALUSIVOS A LA PROPIEDAD CONCEJIL EN GATA
}

\author{
FRANCISCO JAVIER GIL JACINTO \\ Universidad de Sevilla
}

\begin{abstract}
Resumen
En este artículo se analiza un grupo de topónimos menores de Gata (Cáceres) que deben su origen al carácter concejil de los terrenos a los que nombraban en el momento de ser creados, principalmente, a lo largo de los siglos XV y XVI, que es cuando la villa empezó a cobrar cierta importancia con respecto a otras de la Orden Militar de Alcántara. A partir de su creación, el mantenimiento y la extinción de estos onomásticos de lugar han estado sujetos a condicionantes tanto de índole lingüística como de otro tipo.

Palabras clave: Gata, concejo, baldío, ejido, dehesa.
\end{abstract}

\section{PLACE NAMES REFERRING TO THE PUBLIC OWNERSHIP OF LAND IN GATA}

\begin{abstract}
This article analyzes a group of toponyms in Gata, in the province of Cáceres, which reflect the public ownership of the land named, mainly throughout the 15th and 16th centuries, when the town began to gain some importance because it belonged to the Military Order of Alcántara. From then on, the survival or disappearance of names has been subject to both linguistic and extra-linguistic conditions.
\end{abstract}

Keywords: Gata, Council, barren land, common land, pasture.

Fecha de recepción: 8 de abril de 2019 .

Fecha de aceptación: 13 de mayo de 2019. 
1. INTRODUCCIÓN: EL PASO DE LO COMUNAL A LO CONCEJIL Y SUS IMPLICACIONES EN LA TOPONIMIA

La historia de Gata, a partir de la Reconquista, va unida a la de la Orden de Alcántara, que ejercía su jurisdicción sobre la villa a través de la encomienda de Santibáñez el Alto. Esta circunstancia provocó a lo largo del siglo XV una serie de pleitos relativos a las asignaciones de terrenos y a los deslindes entre Gata con Santibáñez y con las demás villas comuneras, los cuales aparecen recogidos en diversos pasajes de la Crónica de la Orden de Alcántara (Torres y Tapia, 1763: II, 262, 329 y 530). La situación de dependencia de Gata con respecto a la Encomienda de Santibáñez cambia en el siglo XVI gracias a la reforma política de Felipe II, consistente en quitar poder a las órdenes de caballería para dárselo a los municipios, que empezaron a gozar de plenos derechos y de una administración que «resultaba muy provechosa por las pingües rentas y hermosos montes que administraban» (Guerra Hontiveros, 1897: 79). De ese modo, a finales del Antiguo Régimen, Gata formará parte de ese casi sesenta por ciento de municipios de la provincia de Cáceres, cuyos concejos, de acuerdo con Melón Jiménez (1989: 277), eran los mayores hacendados del lugar al poseer la titularidad de las tierras comunales.

Para Riesco Roche (2006: 94), quien se acerque al origen de los bienes comunales deberá hacerlo a partir de la Reconquista y de la política repobladora de la época. Este tipo de propiedad, de acuerdo con Nieto García (Lacruz Berdejo, 1965), le fue atribuida inicialmente a los vecinos, pero a lo largo de la Edad Media fue sufriendo una serie de transformaciones jurídicas por las que los concejos terminaron arrogándose el título nominal de dichos bienes, con el desplazamiento subsiguiente de los derechos de aprovechamiento de los vecinos al Concejo. Lacruz Berdejo resume el proceso de ocupación comunal por las gentes del norte de las tierras yermas abandonadas por las gentes del sur y su posterior conversión en concejiles del siguiente modo:

Los bienes comunales durante los primeros siglos de la Reconquista se atribuyen a los vecinos y moradores de un lugar, a los presentes y a los que han de venir; con otras palabras, a una mera agrupación de vecinos. Pero hacia el siglo XIII se introduce una técnica jurídica romanista que niega personalidad a estas agrupaciones, las considera incapaces para ser titulares de derechos y obligaciones [...] así, 
el común de vecinos se ve suplantado por una universitas, por el municipio (Lacruz Berdejo, 1965: 710).

Gata es uno de esos núcleos de población surgidos durante la Reconquista en el que los bienes vecinales irán pasando a ser bienes concejiles, y que, finalmente, sortearán las leyes desamortizadoras del siglo XIX mediante su declaración de montes exceptuados.

\section{CONSIDERACIONES DE TIPO METODOLÓGICAS}

Paralelamente al proceso jurídico relacionado con los cambios en el peculiar modelo de titularidad del suelo, en el plano lingüístico se habrían generado una serie de términos de tipo legal para referirse a la idiosincrasia reguladora de cada uno de los bienes administrados por los gobiernos locales. Con el paso del tiempo, esas denominaciones cristalizarían en los topónimos que constituyen el corpus de este trabajo.

En definitiva, el minicorpus con el que se va a trabajar está compuesto por topónimos cuya motivación semántica se relaciona directamente con la naturaleza jurídica y el sistema de aprovechamiento de la tierra a la que nombraban. Para su estudio, se seguirá el modelo de investigación que Gordón Peral (2014) aplica a corpus toponímicos de un campo semántico determinado. El estudio léxico-semántico de las voces en las que están basados los onomásticos de lugar se realizará teniendo en cuenta las definiciones del Diccionario de Autoridades, por ser este el más cercano en el tiempo a muchos de los documentos consultados. Es decir, se procederá al análisis lingüístico de sustantivos comunes de tipo geográfico, administrativo y económico referidos a la titularidad concejil del suelo que con el tiempo terminaron adquiriendo la condición de nombres propios. Su conversión en topónimos explicaría las razones de por qué algunos de tales apelativos han podido sobrevivir a los cambios de utilidad y al régimen de propiedad de los lugares designados. Para la consecución de los objetivos propuestos se utilizarán, además de los datos lingüísticos, los obtenidos a través de las fuentes documentales antiguas, los proporcionados por los naturales del lugar, la cartografía y los registros catastrales. Será la combinación de todos ellos lo que facilite extraer conclusiones sobre la historia lingüística y no lingüística del área investigada; en este caso, el municipio cacereño de Gata. 


\section{ESTUDIO TOPONOMÁSTICO}

\subsection{Topónimos alusivos a terrenos de propiedad concejil}

La evidencia toponímica relativa a la titularidad concejil de la mayor parte del término municipal de Gata se encuentra en la siguiente serie de topónimos menores:

\subsubsection{Primer grupo: Baldío Almenara y Baldío Cabril}

La voz baldío está documentada desde el siglo XIII como derivado de balde, proveniente del árabe bâtil 'vano, inútil' ( $D C E C H$, s. v. balde). Nebrija, por su parte, lo recoge con el significado de 'tierra que no se labra' (NTLLE, s. v. baldío) y la Real Academia de la Historia, con el de 'tierras concejiles que ni se labran ni se adehesan' ( $D V G E$, s. v. baldío, anexo). Por su parte, Riesgo Roche (2006: 96) destaca su condición de 'tierras incultas y pobres, de aprovechamiento exclusivamente ganadero y uso comunal'. De todo ello se deduce que el significado etimológico 'vano e inútil' lo mantiene únicamente con ciertos matices, ya que, como explica Martín Martín (1990: 11), aunque en su origen se trataba de terrenos que no se hallaban sujetos a cultivo ni contaban con titular dominical expreso, a lo largo del siglo XV se encontraban bajo la autoridad concejil, que regulaba su explotación comunal a través de ordenanzas. Pero, naturalmente, el aprovechamiento y el bajo rendimiento de estas tierras venían condicionados por su baja calidad, su lejanía y su estructura geomorfológica.

No obstante, los baldíos de Gata, al tratarse de extensiones de terrenos de muchas hectáreas, no responden con exactitud a las características de lejanía ni de tierras estériles en parajes escarpados, pues buena parte de ellos se encuentran más próximos al casco urbano y en lugares más llanos y accesibles que las fincas particulares de algunos vecinos. De la idoneidad de parte de estos baldíos para el cultivo queda constancia en una orden dada por el emperador Calos V, seguida por la justicia de Gata, para que «planten pinos y olivos en la parte y lugar de los Valdíos que mas acomodo y conveniente sea, y lo que se gasta en dicha plantación y en beneficiarla y cuidarla, sea a costa de los propios de esta Villa» (Guerra Hontiveros, 1897: 81-82). El mantenimiento de los baldíos gateños debe enmarcarse en el proceso colonizador de la Reconquista, que aseguraba el acceso a ciertos bienes, como la leña, la hierba y la caza, a todos 
los vecinos en los nuevos núcleos de población y evitar así crisis de subsistencia. En el caso de los pastos, el aprovechamiento comunal, sostiene Madoz, excedió, en ocasiones, los límites de los propios concejos o municipios y se practicó «desde muy antiguo en los baldíos de Gata, Santibáñez, El Campo, Hernán Pérez, Torrecilla, Cadalso y Torre de Don Miguel, pudiendo los ganados de unos pastar de manera recíproca en cualquiera de ellos» (DGEH, s. v. Gata).

El valor semántico de 'propiedad comunal' del término baldío se manifiesta en un uso particular del mismo registrado entre los hablantes gateños, donde, además del sentido general 'monte público', se registra también el de 'persona que lo da o lo comparte todo'. Sin embargo, su cristalización en forma toponímica parece haber ocurrido tardíamente en Gata. De hecho, los topónimos compuestos con el elemento Baldío no cuentan con arraigo entre sus habitantes, quienes suelen referirse a ellos con el nombre común monte. El sentido 'terreno concejil' de monte, por oposición a 'tierra de propiedad particular', se encuentra presente en documentos del siglo XVI; como en este, relativo a una de sus ordenanzas municipales de 1518, en el que se dice que la ordenanza «que habla de los fuegos es justa y neçesaria y si no fuese por la pena de dicha hordenança se quemarian los montes y las eredades y aun las casas» ${ }^{1}$.

Respecto a la denominación Baldío Almenara, solo se ha podido documentar tardíamente en un Boletín Oficial de la Provincia de Cáceres (27 de junio de 1906, n. ${ }^{\circ} 153,610$ ); por lo que cabe considerarlo una designación restringida al ámbito administrativo. El complemento del nombre del núcleo toponímico Baldío hace referencia al lugar en que se ubica, Almenara, el cual toma su nombre de una antigua torre de vigilancia. El paraje fue inscrito como monte de utilidad pública en 1931 (Santos Mérida, 2009: 136-141), por considerarse de interés social al estar vinculado al régimen de aguas de la Sierra de Gata.

Un segundo topónimo compuesto que incluye la forma Baldío es Baldío Cabril, que solo ha podido documentarse en fuentes relativamente recientes y con distintas variantes: Dehesa Baldío Cabril (BOP de Cáceres, 17 de octubre de 1890, n. ${ }^{\circ}$ 63, 1), Valdío Cabril (ADP, 12 de diciembre de

${ }^{1}$ La villa de Gata defiende la idoneidad de sus ordenanzas y la adaptación de las innovaciones a la realidad del momento. 1519. Abril, 5. Ávila. A. G. Simancas, Consejo Real, legajo 612, nº 1, fol. 33 r (Clemente Ramos, 2008: 1670). 
1897, fol. 54 v) y Monte Baldío Cabril (BOP de Cáceres, 10 de agosto de 1906, n. ${ }^{\circ}$ 191, 763). Como nombre común a "valdíos desta villa» existen referencias al lugar en el Catastro de Ensenada (CME: Seglares I, fol. 6 v). En la actualidad, los habitantes de Gata no lo nombran por ninguna de estas variantes en las encuestas toponímicas y se refieren al sitio únicamente por su segundo elemento El Cabril, que como monte público sí aparece documentado ya en el primer cuarto del siglo XV en relación con el fuego que el hijo de un tal Juan Blasco «avía dado en el Cabril» (COM, fol. $20 \mathrm{v})$.

Las referencias indirectas al Baldío Cabril, aunque siempre bajo la denominación de Monte Conzejil, no faltan en el Catastro de Ensenada a la hora de señalar los límites de varias fincas con las que confronta en algunos de sus vientos (CME, Seglares II, fol. 369 r y 401 r). El último deslinde del baldío tuvo lugar el 24 de mayo de 2018, fecha en la que se dieron "por finalizadas las operaciones materiales de apeo en segunda fase del deslinde total administrativo del Monte de Utilidad Pública n. ${ }^{\circ}$ 12, denominado "Baldío Cabril", situado en el término municipal de Gata $»^{2}$.

\subsubsection{Segundo grupo: El Lejío, El Ejido Helechoso y Calle Extremo}

Otros nombres de lugar relacionados con la titularidad municipal del suelo son El Lejío, El Ejido Helechoso y Calle Extremo. La voz ejido se documenta en castellano por primera vez en 1100, proveniente del latín EXIRE 'ir o salir' ( $D C E C H$, s. v. salir). Su sentido etimológico 'campo que está a la salida del Lugar' es recogido por Autoridades, que añade los de 'que no se planta ni se labra, y es común para todos los vecinos, y suele servir de era para descargar en él las miesses y limpiarlas' ( $D A$, s. v. exido). Las referencias al ejido de Gata se documentan tempranamente en sus ordenanzas de 1515-1518, donde se dice:

[...] que ninguno sea osado de hacer palomar en el exido desta villa so pena de dosmil mrs. para el conçejo, e que el dicho conçejo se lo pueda derrivar el dicho palomar [...] que por cada cabeça de ganado menor que se hallare en la sierra o en el exido desta villa que pague

${ }^{2}$ Comunicación del trámite de audiencia y vista de la segunda fase del expediente de deslinde del Monte de Utilidad Pública ${ }^{\circ} 12$ Baldío Cabril, sito en Gata (Cáceres). N/Ref.: 1610DL0001. Consejería de Medio Ambiente y Rural, Políticas Agrarias y Territorio. Junta de Extremadura, 25/06/2018 (Archivo personal del autor). 
el dueño quatro mrs. de día e si se allare de noche que pague ocho mrs. [...] (Clemente Ramos, 2008: 1654-1656).

Obsérvese que la utilización que se hace del término es la de un sustantivo común y referido exclusivamente a su uso para el ganado mayor de la villa. Esto parece poner de manifiesto que la función y utilidad de los ejidos habrían diferido de unos concejos a otros, pues mientras las ordenanzas de Gata restringían su uso de ganado menor, las de Valencia de Alcántara, otra de las villas dependientes de la orden alcantarina, permitían que «en los dichos lugares puedan, syn temor de pena, traer sus gallinas y aves mansas y cada, cuatro o finco puercos o puercas, y las bestias que cada uno toviere qualquier que sean, y las vacas y cabras de leche» (Martín Martín, 1990: 25).

En cuanto a la característica definidora de la cercanía o lejanía, esta no se cumple tampoco en ninguno de los ejidos gateños. Ello vine a corroborar la imprecisión terminológica señalada por García García (1983: 26) entre baldío, extremo y ejido; si bien, para el último término se ha hablado, a veces, de un doble tipo: uno situado en el ruedo de los pueblos, que se corresponde con el sentido preciso del término, y otro más alejado, equivalente a los baldíos.

Por lo que se refiere al lugar conocido hoy como El Lejío, fruto de la evolución de El Ejido por un fenómeno de fonética sintáctica y posterior restitución del artículo, tiene la particularidad de encontrase en el punto de confluencia de los términos de las villas de Santibáñez el Alto, Torre de Don Miguel y Gata, pero a varios kilómetros de los cascos urbanos de todas ellas; por lo que en ningún caso podría aplicársele su sentido etimológico de 'lugar a la salida de poblado', lo cual redunda en la imprecisión del contenido semántico de los nombres referidos a las tierras de los concejos.

Por lo que respecta al topónimo Ejido Helechoso, su cristalización no ha podido documentarse hasta 1890 , y únicamente con el nombre Dehesa Ejido Helechoso (BOP de Cáceres, 17 de octubre de 1890, n. ${ }^{\circ}$ 63, 1). Solo en 1897 aparece registrado ya como Egido Helechoso ( $A D P, 12$ de diciembre de 1897, fol. 54 v), y lo mismo en el Catálogo de montes exceptuados (CMDTFE, 1901: 110-111). De ello se desprende que las denominaciones Baldío, Ejido y Dehesa no llevan aparejado un régimen de pro- 
piedad y uso específico para los propios y los forestales de los ayuntamientos distintos en cada caso, sino que todas ellas se refieren al Ejido Helechoso con la consideración de 'monte concejil', tal como se expresa en el Catastro de Ensenada, aunque las referencias al Monte de Helechoso se retrotraen al Libro de la Montería de Alfonso XI (1582: fol. 73 $\mathrm{v})$.

La voz extremo con el sentido de 'zona de pastos' entró tarde en los diccionarios en lengua castellana. El primero en incluirla fue el de la Real Academia de 1803, que la define como 'el invernadero, ó agostadero de los ganados trashumantes' (NTLLE, s. v. extremo); aunque el de Autoridades sí que incluía la perífrasis Ir o passar a extremo el ganado 'mudar de parages para gozar de los pastos, dehesas y montes en los tiempos de Invierno y Verano' ( $D A$, s. v. extremo). En Gata, esta forma extremo con sentido geográfico solo perdura en el odónimo Calle Extremo. Su ubicación, efectivamente, en uno de los extremos del pueblo y al lado de Calle Campito, hace pensar que ambas vías de comunicación tienen su origen en terrenos de uso colectivo.

\subsubsection{Tercer grupo: Dehesa de la Sierra, Dehesa Boyal, La Dejesilla y El Coto}

La llamada dehesa concejil, de acuerdo con el Diccionario de Autoridades, es 'La que tiene el Concejo de algún Lugar, para que pasten en ella los ganados de sus vecinos' ( $D A$, s. v. dehesa). Para Montaña Conchiña (2003: 238-240), el término evolucionó de su significado inicial económico, 'acotamiento de pastos perteneciente a una comunidad', a uno jurídico en el que se solapaban diversas realidades, privilegios y derechos enfrentados, lo que en la práctica supuso que, en ocasiones, se dictaran disposiciones prohibiendo cerrar dehesas que impidieran el acceso a las cañadas trashumantes, mientras que en otras se favoreció el paso del uso público al privado.

Las fuentes más antiguas se refieren a La Dehesa de la Sierra de Gata por el nombre La Sierra; como esta, donde se dice: «Mas, resçibi de Min Blasco seiscientos maravedis que dio porque el conçejo le dexo traer en la sierra çiertos borregos» (COM, fol. $12 \mathrm{v}$ ). Solamente en documentos de los siglos XVIII y XIX, como en los reproducidos a continuación, empieza a recibir el nombre de Dehesa de La Sierra: 
A la Vigesimo tercia Digeron que los propios que tiene esta villa son dos Dehesas, la una nombrada de la Sierra de pasto baxo arrendada oy a Don Franzco. de Ontiveros [...] (CME, Respuestas generales, fol. $27 \mathrm{r}$ ).

La Dehesa de la Sierra se haya la mayor parte poblada de arbustos de mata o roble $[. .$.$] son montes públicos y pertenecen a los propios$ de esta villa y están mal parados por el descasque, cortes y talas que se hacen fraudulosamente. Interrogatorio de la Real Audiencia de Extremadura de 1791 (Rodríguez Cancho y Barrientos Alfageme, 1993: 287).

Y por último la llamada dehesa de la Sierra, que comprende 3/4 leguas de E. a O. y $1 / 2$ de $\mathrm{N}$ a Sur, bien poblada de robles y que produce algunos pastos (DGEH, s. v. Gata).

[...] en el término de este Pueblo hay una pequeña dehesa poblada de roble alto y bajo llamada Sierra $(A D P, 19$ de marzo de 1882, fol. $7 \mathrm{v}-8 \mathrm{r})$.

A pesar de incluir el elemento Dehesa, el topónimo La Dehesa de la Sierra nombra un terreno completamente abierto; por lo que, en este caso, el término habría perdido su sentido etimológico de 'tierra defendida o acotada'. Dicha pérdida es común en otras partes de la Península, y Gordón Peral (1988: 152) recuerda que existió la expresión dehesa adehesada, quizás refuerzo más que redundancia si se tiene en cuenta que pronto dejaría de tenerse conciencia del significado original para pasar a sentirse como sinónimo de 'baldío o majada'. En la Sierra de Gata, este significado se puede rastrear en el nombre de lugar Dehesa Majadal y Bardal de Hernán-Pérez (IDEEX).

El hecho de no estar vallada no quiere decir que La Dehesa de la Sierra no estuviera delimitada y que no se persiguieran las rozas ilegales. Prueba de ello es el minucioso deslinde realizado en 1802 a petición de los señores diputados de la Pastancia Boyal, a quienes había llegado «noticia que algunos vecinos han echo y estan haciendo algunas eredades en la Dehesa Boyal de la Sierra, quitando Cañadas y haciendo cercas en grande perjucio de esta Boyada y del Arbolado» («Deslinde y delimitacion de la Dehesa de la Sierra», fol. 13 r). 
En cuanto al onomástico La Dehesa Boyal, cabe interpretarlo, de acuerdo con la información de la cita anterior, referido a una parte de $\mathrm{La}$ Dehesa de la Sierra reservada para el ganado del Concejo y que se situaba, según un documento de deslinde de 1902, junto al sitio denominado «"La Almenara" [...] en linde que separa al N. la Dehesa Boyal del pueblo de Gata, y al S. en término de Santivañez el Alto» (CAR, «Acta de reconocimiento de deslinde de Gata y Santivañez el Alto", fol. 8 v).

De acuerdo con la documentación anterior, su utilidad se correspondía, a grandes rasgos, con la definición de la Real Academia de la Historia cuando se refiere a las dehesas boyales como aquellas 'destinadas al pasto del ganado de labranza, y del cerril' ( $D V G E$, s. v. dehesa), aunque en la vecina población de Coria, en ocasiones, pueda adquirir el sentido de 'tierra de pasto que es propiedad de todos los vecinos del pueblo' (Cummins, 1974: 123). La delimitación terminológica y el uso de los distintos tipos de terrenos concejiles se observan también en la siguiente cita referida a los propios de la villa de Gata consistente en «dos Dehesas, la una nombrada de la Sierra de pasto baxo, arrendada oy a Don Franzco. de Ontiveros en trescientos y sesenta [maravedís] vaxo la condición de servir de exido patero ó Dehesa Boyal para el ganado del Concejo cabrio, Bueyes de Labor y caballería» ( $C M E$, Respuestas generales, fol. 27 r).

A esta imprecisión terminológica contribuyó el que muchas de las dehesas, que en la actualidad aparecen señaladas como boyales, lo son fruto de una artimaña legal de los ayuntamientos para esquivar las leyes desamortizadoras del siglo XIX, mediante la cual fueran exceptuados de su venta los ejidos y los baldíos de los pueblos. Y así ha quedado reflejado en el libro de actas de sesiones de la época del ayuntamiento de Gata:

[...] el tribunal Gubernativo del Ministerio de Hacienda se há resuelto con fecha 11 de Noviembre último que se exceptúen de la venta los terrenos de este término denominados «Valdío Cabril» y «Egido Helechoso» en concepto de dehesa boyal [...] (ADP, 12 de diciembre de 1897, fol. $54 \mathrm{v}$ ).

Un tercer topónimo, formado a partir de dehesa más el sufijo -illa, es La Dehesilla o Dejesilla. Gordón Peral (2002: 1513-1514) plantea dos posibilidades para la interpretación y motivación toponomástica del morfema diminutivo: una es la de considerar su sentido cuantitativo, en tanto que se trataría de una 'dehesa pequeña', y otra, la de atender a su aspecto 
cualitativo, es decir, en su importancia relativa con respecto a otra mayor o principal de la que se ha desgajado; en este caso, una zona concreta de la Dehesa de la Sierra. La Dehesilla aparece documentada en unas ordenanzas de 1533 que regulaban el acceso y disfrute de los montes comuneros de Gata, Torre de Don Miguel, Villasbuenas y Santibáñez, y en las que se dice que «los lugares de Hernán Pérez e Torrezilla e Cadalso no son comuneros en el monte o territorio que dizen de la Dehesilla, excepto las dichas quatro villas y el lugar del Campo» (Ordenanzas del monte, 1533, fol. $22 \mathrm{v})$.

El sentido de 'tierra defendida' de la voz dehesa se encuentra también en coto, procedente del latín CAUTUM 'disposición preventiva de las leyes', que en el bajo latín español pasó a significar 'mojón' y 'terreno acotado' ( $D C E C H$, s. v. coto), y que Covarrubias, a principios del siglo XVII, recogía como 'el término de lindero de pasto y dehesas' (TLC, s. v. coto). Es decir, habría ido adquiriendo gradualmente el sentido típicamente toponímico que aparece en Autoridades: 'La dehessa o término cerrado, donde está vedado y defendido el entrar a pastar' ( $D A$, s. v. coto). Esta misma evolución semántica se advierte en el origen de Los Cotos, que en un mismo escrito aparece como sustantivo común y como nombre propio:

Un castañar [...] poblado con ziento ochenta y siete pies de castaños injertos al sitio de los cotos término de esta villa, dista un quarto de legua larga de esta población. Confronta a los quatro vientos con cotos de esta villa ( $C M E$, Seglares I, fol. 6 v).

Finalmente, la forma que acabará fijándose en la toponimia es la variante singular El Coto, que en el Registro de la Propiedad de Hoyos aparece inscrita como finca rústica «en Coto, de las Ánimas de Gata, censo, en 1793» (BOP de Cáceres, 29 de septiembre de 1863 , n. ${ }^{\circ} 117,3$ ); sin embargo, esta forma singular está también presente en la denominación «trepollar de el Coto» (CME, Seglares I, fol. $261 \mathrm{r}$ ) y "Barrancas del Coto» que «Confronta L. y S. Coto de esta» (CME, Seglares III, fol. 1316 v).

3.2. Topónimos basados en nombres geográficos con el sentido secundario de 'tierras del concejo'

\subsubsection{El Valle, El Valle La Puente y La Marrada}

La voz valle 'llanura de tierra entre montes, ò alturas' ( $D A$, s. v. valle) se encuentra suficientemente representada en la toponimia gateña, pero 
en este trabajo solo se estudiarán dos de esos valles, que, además de responder a la definición de Autoridades, retienen los rasgos distintivos de 'uso comunal' y de 'campo no arable'. Con respecto a la primera característica, cabe relacionar estos valles con los pastizales de otras zonas ganaderas extremeñas a las que Devillard (1993: 250-251) se ha referido como «valles en proindiviso». En relación con la característica de 'terreno no cultivado', Llorente Maldonado (1991: 548) verifica este significado secundario en zonas de la cuenca del Duero, donde toda la tierra aprovechable está labrada, excepto algunos de estos pequeños valles. Es decir, mantendría un sentido similar al de baldío, y es en este significado donde se encontraría el origen de los topónimos El Valle y El Valle La Puente.

En la actualidad, El Valle podría considerarse extinto, aunque se encuentra bien documentado en el Catastro de Ensenada (CME, Seglares I, fol. 195 v, 344 r y Seglares II, fol. 389 r-v) y en un deslinde anterior (Visita de la Cañada de la Cruz de Piedra. 1716, fol. 11 v) que lo sitúa en los aledaños de la Dehesa Boyal y de un paso de ganados, lo cual explicaría la motivación toponímica basada en la acepción 'pastos de uso comunal' de la voz valle. La pérdida de vigencia del topónimo parece consecuencia del cambio de uso de la tierra, provocado, principalmente, por la disminución de las cabezas de ganado y, en menor medida, por su alejamiento del casco urbano.

Contrariamente a lo que ocurría con El Valle, la localización de El Valle de la Puente, a la salida del pueblo, ha coadyuvado a la conservación del onomástico y en la del uso comunal por los vecinos, que todavía hoy llevan a pastar en él las pocas cabezas de ganado que quedan. Como nombre de lugar, el Catastro de Ensenada lo menciona tanto con su forma masculina "valle de el Puente» (CME, Seglares I, fol. 308 v) como con la femenina medieval «valle de la Puente» (CMS, Seglares II, fol. 464 v), que es la usada por Guerra Hontiveros (1897: 33) y los demás vecinos del pueblo. Su uso comunal se desprende de la siguiente orden municipal para que en un plazo acordado se «retiren los ganados de todas clases de las haciendas, que se prohiva la entrada de estos en las marradas, en las vegas de los ríos, y en el valle del puente $[\ldots] »(A D P, 21$ de septiembre de 1884 , fol. 25 r).

La orden anterior nos sirve, a la vez, para interpretar el termino marrada con el sentido de 'zona de pasto comunal', similar al de valle. Sin 
embargo, marrada no aparece en el $N T L L E$, aunque sí marra 'falta de alguna cosa, donde había de estar. Usase freqüentemente hablando de las viñas, donde en los liños faltan cepas, y se dice que tienen muchas marras' ( $D A$, s. v. marra). En la vecina Coria, marra es un 'trozo de monte donde es imposible labrar' (Cummins, 1974: 117); Llorente Maldonado (1991: 549) la verifica como 'parte abrupta del terreno en la que no entra el arado y se trabaja con azada' en la provincia de Salamanca, donde en la vertiente norte de la Sierra de Gata marrá o marrada significa 'riberas, barrera' (Alonso Pascual, 2002: 263); y en el ámbito de las hablas leonesas, marrá son los 'pastos comunales que quedan en la hoja sembrada' (DHL, s. v. marrá).

La asociación entre ambos sentidos de marrá 'tierra sin cultivar' y 'uso comunal' nos lleva a interpretar el origen del topónimo La Marrada de Gata como un 'lugar de aprovechamiento comunal donde pastaba el ganado'. Se trata, sin duda, de una creación toponímica tardía, pues en el Catastro de Ensenada no se menciona, pero sí en el de 1940 (TTCP1, pol. $3,1)$.

\subsection{Topónimos alusivos a la institución municipal}

\subsubsection{Primer grupo: La Joya los Consistorios, El Concejo y El Pago de la Villa}

En este apartado se analizan topónimos que incluyen algunos de los nombres comunes empleados para referirse a la institución municipal, pero con el significado accesorio de 'suelo concejil'. La impresión primera, de acuerdo con las definiciones de concejo 'Ayuntamiento o Junta de la Justicia y Regidores que gobiernan lo tocante al público de algúna Ciudad, Villa o Lugar' ( $D A$, s. v. concejo); de consistorio 'en algúnas Ciudades y Villas principales de España se llama assí el Ayuntamiento o Cabildo Secular y Regimiento, compuesto del Corregidor, Alcalde y Regidores' ( $D A$, s. v. consistorio); y de villa 'se toma también por el cuerpo de los Regidores, y Justicias, que le gobiernan' ( $D A$, s. v. villa), es que se trataría de términos cuasi sinónimos.

Respecto a la presencia en la toponimia de Gata de la forma Concejo, existe una primera mención en el Catastro de Ensenada para referirse a un "Castañar que llaman de concejo» (CMS, Respuestas generales, fol. $27 \mathrm{v}$ ), perteneciente a los propios de la villa, en la que es difícil saber si 
castañar es un nombre común o forma parte de uno propio Castañar del Concejo. Una segunda mención a una viña particular que «confronta al Norte con camino de el castañar de conzejo» (CME, Seglares I, fol. 247 v) tampoco permite categorizarlo claramente como nombre propio, pero sí un escrito posterior en el que se habla de la petición por parte de un vecino de "huebra y media de terreno al sitio de el Castañar del Concejo» («Auto para el Escribano del Ayuntamiento», fol. 11 r). Sin embargo, la vigencia de la variable compuesta Castañar del Concejo fue breve, ya que, medio siglo después, en un anuncio de ventas de propiedades y derechos del Estado se mencionaba «un castañar de 44 piés al Concejo, término de Gata de sus propios» (BOP de Cáceres, 6 de mayo de 1859, n. ${ }^{\circ} 117$ ). A partir de entonces, es decir, tras su desamortización, la forma Concejo o El Concejo es la que aparece siempre en los registros cartográficos y catastrales (TTCP2, pol. 3, 4, LRDR y MPC50). El paso de las tierras concejiles a manos privadas tiene su origen, según Hinderink (1963: 59), en el aumento continuado de la población en los años posteriores a la elaboración del Catastro de Ensenada, que obligó a algunos municipios de la Sierra de Gata a vender parte de sus bienes concejiles o propios a sus vecinos. El cambio de la propiedad concejil a la privada queda reflejado en el topónimo menor Concejiles de don Claudio en la Villa del Campo (IDEEX), que, como la de Gata, fue dependiente, en tiempos, de la Encomienda de Santibáñez. En el Castañar del Concejo, la tala de los castaños tras su desamortización y la extensión del nombre a las fincas colindantes, principalmente prados, habrían hecho que el elemento Castañar desapareciera.

A pesar de que concejo y consistorio resulten prácticamente sinónimos, el paso de uno y otro a la toponimia extremeña no ha seguido igual suerte. De hecho, solo se ha podido documentar un Cerro del Consistorio en Cáceres (IDEEX), y, como forma oral, La Hoya de los Consistorios en Gata. La voz hoya, además de su sentido topográfico de 'hondonada', tiene para los gateños otro más específico de 'zona abrigada en la montaña', que en este caso equivale a decir 'bueno para pastos'. Esta última cualidad estaría en consonancia con el hecho, señalado por Martín Martín (1990: 27), de que las dehesas concejiles que se encontraban en terrenos comunales favorecieran una reserva de usufructo a determinados grupos sociales. Tal afirmación, referida a La Hoya de los Consistorios, dado el sentido posesivo de la preposición de, hace pensar que habría 
beneficiado de manera particular a los miembros del Consistorio, ya que «alcalde, regidores y mayordomos carecen de salario pero tienen importantes compensaciones legales y extralegales» (Martín Martín, 1969: 107).

En la actualidad, las voces concejo y consistorio no están presentes en el habla viva de Gata; perviven únicamente fosilizadas en su forma toponímica. Por el contrario, villa sigue formando parte del léxico local y ha mantenido un sentido de 'bien comunal' a través del tiempo. Así, hasta la desaparición a finales del siglo pasado del rebaño comunal, se hablaba de «las cabras de la villa», y hoy día se sigue usando en expresiones como «el reloj de la villa». Este mismo sentido se verifica en la comarca salmantina de El Rebollar, donde la propiedad comunal suele indicarse mediante las formas «de la villa o concejo» (Iglesias Ovejero, 1982: 171). La sinonimia de los términos villa y concejo en Gata se evidencia en documentos antiguos en los que el referido «rebaño de la villa» se nombraba como la «cabrada de concejo» ("Deslinde y delimitación de la Dehesa de la Sierra», fol. 17 r). De ello se desprende que el elemento Villa, del topónimo extinguido El Pago de la Villa, se haya que interpretar como 'tierra de propiedad concejil'. La existencia de este pago se infiere de manera indirecta de una relación del Catastro de Ensenada al huerto de un vecino "al sitio de el Pago de la villa ynmediato a ella» (CME, Seglares II, fol. 364 r), pero es evidente que antes de su cristalización como topónimo debió de existir dicho pago como realidad física y jurídica.

La interpretación de la forma Villa con el significado de 'órgano municipal' permite, a su vez, por una relación de metonimia, aplicarla al nombre propio de la villa en cuestión, es decir, Gata, a la hora de interpretar el topónimo El Castañal de Gata como 'bien de propiedad concejil'. Aunque se trata de un topónimo extinguido, de acuerdo con el lugar donde las fuentes lo sitúan, podría tratarse de una variante de El Concejo o Castañar del Concejo, lo que evidenciaría que las formas Villa, Gata y Concejo son, efectivamente, equivalentes:

Mas adelante en el monte cerca de la vereda que pasa por el castañar que llaman de gata yendo hacia arriba para las viñas del zerro [...] (Deslinde de Gata con Torre, fol. 5 r). 
Esas mismas fuentes muestran el paso del uso del nombre de Gata para referenciar un castañar en concreto a su forma toponímica para nombrar una zona:

María Cardona: Tiene una viña [...] al sitio del Castañar de Gata (CME, Seglares III, fol. 1423 r).

Francisco Barrera: Otra Viña de tres quartas de Tierra de M. C. poblada con 200 vides al sitio del Castañar de Gata (CME, Seglares III, fol. 1419 r).

\section{CONCLUSIONES}

Una vez analizado este micro corpus de topónimos menores, interesa conocer también la trayectoria vital de cada uno de ellos; es decir, su vigencia y el impacto que siguen teniendo en la vida económica y social de los naturales que los utilizan o han dejado de hacerlo. En primer lugar, hay que considerar el grupo de los topónimos extintos; esto es, aquellos de los que solo queda memoria en los registros cartográficos o catastrales. La desaparición de El Pago de la Villa y El Castañar de Gata sería achacable al cambio de titularidad de la tierra, si bien esta es una regla que no se cumple en el caso de El Coto, El Lejío, El Concejo y El Campito, convertidos ahora en lotes de tierra en manos de particulares, y este podría ser el motivo de su conservación, la necesidad continua de nombrarlos. Lo mismo ocurre con los fosilizados en los odónimos La Calle Campito y La Calle Extremo.

La utilización de manera continuada como pastizal de libre acceso habría sido determinante para que La Hoya de los Consistorios, La Dehesilla, La Marrá y El Valle de la Puente cuenten con gran vitalidad hoy en día. Por el contrario, El Valle, que, sin duda, habría sido una zona de pastos anteriormente, ya en tiempos del Catastro de Ensenada estaba ocupado principalmente por viñas que luego fueron sustituidas por castaños; por lo que el lugar terminó anexionándose al paraje contiguo llamado Los Castañares.

Por lo que respecta a los nombres de lugar que incluyen los elementos Dehesa, Ejido y Baldío, estos resultan desconocidos para la mayoría de los habitantes de Gata. Su falta de vitalidad se debería en parte a que ya 
no son de ninguna relevancia para los vecinos del pueblo. Pero también a que, como se ha explicado anteriormente, las denominaciones Dehesa de la Sierra, Dehesa Boyal, Baldío Cabril, Baldío Almenara y Ejido Helechoso tuvieron siempre más la consideración de términos administrativos que de topónimos consolidados, con excepción hecha de El Lejío y La Dejesilla, en los que las alteraciones fonéticas habrían contribuido a que perdieran su carga designativa en favor de un valor exclusivamente onomástico.

A la inversa, habría que considerar que los elementos nucleares de las denominaciones Dehesa de la Sierra, Dehesa Boyal, Baldío Cabril, Baldío Almenara y Ejido Helechoso habrían retenido siempre su contenido léxico de 'terreno concejil'; por lo que, al no ser topónimos claramente consolidados, no resistieron el cambio de estatus jurisdiccional y lo que cristalizó fue su segundo elemento, La Sierra, El Cabril, Almenara y Helechoso, que es lo que se ha mantenido estable a lo largo del tiempo, llegando incluso a extinguirse La Dehesa Boyal.

De manera resumida, se puede concluir con que los estudios toponomásticos permiten explicar el contexto lingüístico y extralingüístico en el que los onomásticos de lugar fueron creados; es decir, un estudio de su historia y de su vida como topónimo, pero predecir el futuro que les aguarda es una tarea más problemática.

\section{BIBLIOGRAFÍA CITADA}

ALFONSO XI (1582): Libro de la Montería que mandó escribir el muy alto y muy poderoso rey Don Alfonso de Castilla, y de León, último de este nombre. Sevilla, Impreso por Andrea Pescioni.

Alonso Pascual, J.A. (2002): Robleda: Crónica y descripción del lugar. Salamanca, J.A. Pascual.

$B O P=(1835-1952):$ Boletín Oficial de la Provincia de Cáceres. Biblioteca Virtual de la Prensa Histórica. Ministerio de Cultura y Deporte (en línea: <http://prensahistorica.mcu.es/es/consulta/busqueda.cmd> [consulta: varias fechas, 2019]). 
CMDTFE = (1901): Catálogo de los montes y demás terrenos forestales exceptuados de la desamortización por razones de utilidad pública (Formado en cumplimiento de lo dispuesto en el artículo $4^{\circ}$ del Real decreto de 27 de Febrero de 1897). Madrid, Imprenta de la sucesora de M. Minuesa de los Ríos.

Clemente Ramos, J. (2008): «Ordenanzas de Gata. 1515-1518». Revista de Estudios Extremeños, 64.3, págs. 1639-1671.

Cummins, J.G. (1974): El habla de Coria y sus cercanías. Londres, Tamesis Books Limited.

$D A=(1726-1739)$ : Diccionario de Autoridades. Real Academia Española. Madrid (en línea: <http://web.frl.es/DA.html> [consulta: varias fechas, 2019]).

DCECH = COROMINAS, J. y PASCUAL, J.A. (1980-1983): Diccionario crítico etimológico castellano e hispánico (5 vols.). Madrid, Gredos.

DEVILLARD, M.J. (1993): «La historia y su neutralización en la organización social de las dehesas ganaderas en proindiviso». En Rodríguez Becerra, S. (ed.): Trashumancia y cultura pastoril en Extremadura. Mérida, Asamblea de Extremadura, págs. 249-290.

DGEH = MADOZ, P. (1846): Diccionario geográfico estadístico histórico de España y sus posesiones de ultramar. Madrid, Madoz y Sagasti.

DHL = MinguÉLEZ RodRíGUEZ, E. (1997): Diccionario de las hablas leonesas. Zamora, Montesinos.

DVGE $=(1752):$ Diccionario de voces españolas geográficas. Madrid, Antonio Sanz.

GARCía GARCÍA, J.J. (1983): La toponimia del Bierzo. (Bases para un corpus toponymicum). Tesis doctoral, parte segunda. Madrid, Universidad Complutense.

Gordón Peral, M.D. (1988): Toponimia de la Sierra Norte de Sevilla: Estudio lexicológico. Sevilla, Universidad de Sevilla.

- (2002): «Sobre la significación del diminutivo en la toponimia». Actas del V Congreso internacional de Historia de la Lengua Española. Madrid, Gredos, págs. 1505-1518.

- (2014): «De Toponimia e historia. La referencia a litigios sobre demarcaciones territoriales en la onomástica de lugares hispánicos». Rivista italiana di onomástica, XX.1, págs. 27-48.

Guerra Hontiveros, M. (1897): Apuntes históricos acerca de la villa de Gata. Salamanca, Establecimiento Tipográfico de la Oliva.

HINDERINK, J. (1963): The Sierra de Gata. A Geographical Study of a Rural Mountain Area in Spain. Groningen, J. B. Wolters. 
IgLESIAS OveJERO, Á. (1982): El habla de El Rebollar. Salamanca, Diputación de Salamanca.

LACRUZ BERDEJO, J. L. (1965): «NIETO, Alejandro: "Bienes comunales". Un volumen de 975 páginas. Madrid. Editorial de Derecho Privado, 1964». Anuario de Derecho Civil, 3, págs. 709-713.

LLORENTE MALDONADO, A. (1991): «Las denominaciones de erial en las provincias de Zamora, Salamanca y Ávila». En Dengler Gassin, R. (ed.): Estudios humanísticos en homenaje a Luis Corté Vázquez. Vol. II. Salamanca, Universidad de Salamanca, págs. 539-552.

MARTín MARTíN, J.L. (1969): «Organización municipal de la villa de Gata en el siglo XVI». Annales de la Faculte des Lettres et Sciences Humaines de Nice, 910, págs. 101-124.

— (1990): «Evolución de los bienes comunales en el siglo XV». Studia Historica. Historia medieval, 8, págs. 7-49.

Melón Jiménez, M.A. (1989): Extremadura en el Antiguo Régimen: economía y sociedad en tierras de Cáceres, 1700-1814. Mérida, Editora Regional de Extremadura.

Montaña Conchiña, J. L. (2003): La Extremadura cristiana (1142-1350). Poblamiento, poder y sociedad. Cáceres, Universidad de Extremadura.

Nieto García, A. (1964): Bienes comunales. Madrid, Editorial de Derecho Privado.

$N T L L E=$ Nuevo tesoro lexicográfico de la lengua española. Real Academia Española (en línea: <http://ntlle.rae.es/ntlle/SrvltGUIMenuNtlle?cmd=Lema\&sec= 1.0.0.0.0> [consulta: varias fechas, 2019]).

RIESGO RocHE, S. (2006): «La progresiva privatización de los bienes comunales en el norte de Extremadura». Alcántara, 65, págs. 93-111.

Rodríguez CANCHO, M. y BARRIEnTos Alfageme, G. (1993): Interrogatorio de la Real Audiencia: Extremadura a finales de los tiempos modernos. Cáceres, Universidad de Extremadura.

SANTOS MéRIDA, I. (2009): Catálogos de montes de utilidad pública de Extremadura. Mérida. Junta de Extremadura.

TORRES Y TAPIA, A. (1763): Crónica de la Orden de Alcántara (2 vol.). Madrid, Imprenta de Don Gabriel Ramírez.

ARCHIVO HISTÓRICO MUNICIPAL DE GATA

$A D P=$ Actas del pleno. 1882 a 1899. Sin clasificar. 
«Auto para el Escribano del Ayuntamiento». Expediente de aprovechamiento y disfrute de bienes.1801-1802. Archivo Histórico Municipal de Gata. Sin clasificar. Folios, 1 r-15 r.

$C A R=$ Copia de las actas de reconocimiento y señalamiento de los mojones comunes de los términos municipales de Gata y Payo, de Gata y Acebo, de Gata y Santivañez el Ato y de Gata y Peñaparda. Acta de reconocimiento de deslinde de Gata y Santivañez el Alto. 17 de junio de 1902. Gata. Sin clasificar.

$C M E=$ Catastro del Marqués de la Ensenada. 1753. Respuestas Generales y Seglares I, II y IV. Sin clasificar.

COM = Cuentas y ordenanzas municipales de Gata. 1525-1538. Gata. Sin clasificar.

«Deslinde y delimitación de la Dehesa de La Sierra». Expediente de aprovechamiento y disfrute de bienes.1801-1802. Archivo Histórico Municipal de Gata. Sin clasificar, fol. $15 \mathrm{v}-23 \mathrm{v}$.

Visita de términos entre las villas de gata y la torre. 14 de marzo de 1693. Gata. Sin clasificar.

\section{FUENTES CARTOGRÁFICAS Y CATASTRALES}

IDEEX = Infraestructura de datos espaciales de Extremadura. Junta de Extremadura (en línea: <http://www.ideex.es/IDEEXVisor/> [consulta: varias fechas, 2019]).

$L R D R=$ Libro de registro de derechos reales y contribución rústica de Gata. 24 de octubre de 1974. Alcaldía de Gata.

MPC50 = Mapa de Parcelación Catastral (1987). Tipos de gravamen de la contribución rústica y urbana. Plano de sección del núcleo de Gata. Esc. 1:50.000. Alcaldía de Gata.

TTCP = Trabajos topográficos del catastro parcelario. Instituto Geográfico y Catastral. Oficina de Cáceres. Término municipal de Gata. 2 de enero de 1940. Escala 1:1.000, 1:2.000 y 1:5.000. Alcaldía de Gata.

Francisco Javier GIL JACINTO

Universidad de Sevilla

masefo@yahoo.es

0000-0001-8478-1008 